\title{
Pengaruh service quality terhadap kepuasan pasien ekspatriat klinik gigi Bali International Dental Center
}

\author{
Grace Ayu Prithari ${ }^{1 *}$, Ignatius Setiawan ${ }^{1}$, Chandra Kuswoyo ${ }^{2}$ \\ ${ }^{1}$ Departemen Ilmu Kesehatan Gigi Masyarakat, Fakultas Kedokteran Gigi, Universitas Kristen \\ Maranatha, Indonesia \\ ${ }^{2}$ Departemen Ilmu Manajemen Fakultas Ekonomi, Universitas Kristen Maranatha, Indonesia
}

*Korespondensi : graceayu26@hotmail.com

\begin{abstract}
ABSTRAK
Pendahuluan : Seiring dengan berkembang pesatnya arus globalisasi dan fenomena Masyarakat Ekonomi ASEAN (MEA), jumlah ekspatriat di Pulau Bali meningkat. Para ekspatriat membutuhkan perawatan gigi selama menetap di Pulau Bali. Persaingan ketat di bidang kedokteran gigi menuntut klinik gigi untuk memiliki strategi yang tepat agar dapat bersaing, dan salah satu strategi yang diperlukan adalah menciptakan kepuasan pasien pada klinik gigi. Penelitian ini bertujuan untuk mengetahui pengaruh service quality terhadap kepuasan pasien ekspatriat Klinik Gigi Bali International Dental Center di Denpasar - Bali. Metode: Jenis penelitian analitik. Penelitian ini dilaksanakan pada bulan Juli - Agustus 2017 pada100 pasien ekspatriat di Klinik Gigi Bali International Dental Center. Analisis data menggunakan uji analisis regresi berganda. Pengolahan data menggunakan program SPSS. Hasil : Uji statistik regresi parsial menunjukkan bahwa variabel Tangibles (X1) berpengaruh sebesar 8,0\% terhadap kepuasan pasien, Empathy (X2) berpengaruh sebesar 18,8\% terhadap kepuasan pasien, variabel Reliability (X3) berpengaruh sebesar 15,9\% terhadap kepuasan pasien, variabel Responsiveness (X4) memiliki pengaruh terhadap kepuasan pasien sebesar 28,5\% dan variabel Assurance (X5) berpengaruh sebesar $14,6 \%$ terhadap kepuasan pasien. Simpulan: Kepuasan pasien merupakan persyaratan fundamental bagi penyedia layanan kesehatan. Service quality berpengaruh signifikan terhadap kepuasan pasien. Variabel tangibles (X1) memiliki pengaruh terkecil terhadap kepuasan pasien, sedangkan variabel responsiveness (X4) memiliki pengaruh terbesar terhadap kepuasan pasien.
\end{abstract}

Kata kunci: service quality, kepuasan pasien, klinik gigi internasional

\section{The effect of service quality on expatriate patients' satisfaction at Bali International Dental Center}

\begin{abstract}
Introduction: Along with the rapid globalization and ASEAN Economic Community (AEC) phenomenon, the number of expatriates living in Bali has been increased. The expatriates might need dental care while settling in Bali. Tight competition in dentistry field requires dental clinics to have the exact strategy to compete, and one of the strategies needed is to create patients' satisfaction in dental clinic. This study was aimed to determine the effect of service quality on expatriate patients' in Bali International Dental Center located at Denpasar - Bali. Methods: An analytic study was conducted using cross-sectional study design. The study period was July - August 2017 with as many as 100 expatriate patients' at Bali International Dental Center. The data analysis was performed using multiple regression analysis test. Data analysis was carried out using SPSS ${ }^{\text {TM }}$ program. Results: Tangibles (X1) affected as much as $8.0 \%$ of overall patient satisfaction; empathy (X2) affected 18.8\%; reliability (X3) affected 15.9\%; responsiveness (X4) affected 28.5\%; and assurance (X5) affected $14.6 \%$ of overall patient satisfaction. Conclusion: Patient satisfaction is a fundamental requirement for health care providers. In this study, service quality significantly affects patient satisfaction. Tangibles (X1) has the smallest effect on patient satisfaction, while responsiveness (X4) has the highest influence on patient satisfaction.
\end{abstract}

Keywords : Service quality, patient satisfaction, international dental clinic 


\section{PENDAHULUAN}

Seiring dengan semakin pesatnya perkembangan teknologi informasi dan komunikasi, serta arus globalisasi yang menyebar ke seluruh dunia, maka terjadi pertumbuhan ekonomi serta pertukaran geografis dan budaya antar negara, melalui arus globalisasi tersebut. ${ }^{1}$ Pemerintah Indonesia telah tergabung dalam Masyarakat Ekonomi ASEAN (MEA), yang perjanjiannya disahkan oleh para Kepala Negara/Pemerintah anggota negara ASEAN pada KTT ASEAN ke-27 tanggal 22 November 2015 di Kuala Lumpur. MEA merupakan bentuk integrasi ekonomi regional anggota negara ASEAN. Tujuan utama MEA adalah menjadikan ASEAN sebagai pasar tunggal dan basis produksi, dimana terjadi aliran bebas barang, aliran bebas jasa, aliran bebas investasi, aliran modal yang lebih bebas, serta aliran bebas tenaga kerja terampil. Proses liberalisasi ASEAN secara gradual memberikan kesempatan bagi tenaga kerja terampil yang telah disepakati oleh ASEAN untuk dapat berpindah dari satu negara ASEAN ke negara ASEAN lainnya tanpa mengalami hambatan. $^{2}$

Tenaga kerja asing atau yang biasa disebut ekspatriat adalah warga negara asing yang menetap di sebuah negara. ${ }^{2}$ Jumlah tenaga kerja asing yang masuk ke Indonesia kian meningkat, terutama di Propinsi Bali yang dikenal sebagai pusat pariwisata Indonesia. Tenaga kerja asing yang datang ke Indonesia tidak hanya berasal dari negara-negara ASEAN, namun juga berasal dari seluruh negara di dunia. Jumlah tenaga kerja asing di Provinsi Bali pada tahun 2009 tercatat 1.588 orang dan mengalami peningkatan pada tahun 2010 menjadi 1.756 orang. ${ }^{3}$

Konsep hak asasi manusia sebagai hal yang penting untuk diperhatikan adalah menyediakan dasar proteksi bagi pekerja, termasuk hak perawatan kesehatan. ${ }^{4}$ Kesehatan rongga mulut merupakan hal yang integral dan esensial terhadap kesehatan tubuh secara menyeluruh. Kesehatan rongga mulut memiliki makna yang lebih dari sekedar kondisi gigi yang baik, namun kesehatan rongga mulut meliputi kesehatan secara menyeluruh serta penting bagi kesejahteraan individu. Berbagai penyakit mulut membatasi aktifitas di sekolah, kantor dan rumah yang menyebabkan jutaan jam sekolah dan bekerja hilang setiap tahunnya di seluruh dunia. Terlebih lagi, dampak psiko-sosial dari penyakit ini seringkali mengurangi kualitas hidup individu. ${ }^{5}$ Seiring dengan perkembangan zaman dalam era globalisasi serta adanya fenomena MEA, dokter gigi melayani semakin banyak pasien yang berasal dari berbagai negara. Pertama, semakin banyak orang tinggal sementara di luar negara asalnya karena komitmen pekerjaan. Kedua, semakin banyak pasien melakukan perawatan kesehatan di luar negara asalnya karena alasan waktu tunggu yang panjang, biaya perawatan yang terlalu mahal, ataupun mencari perawatan dengan kualitas yang lebih baik. ${ }^{6}$

Pasien asing terkadang berhadapan dengan tantangan komunikasi terhadap penyedia layanan kesehatan. Hal tersebut merupakan suatu permasalahan penting bagi penyedia layanan kesehatan karena komunikasi dokter-pasien secara keseluruhan turut menentukan kepuasan pasien, yang nantinya akan mempengaruhi hasil kesehatan pasien. ${ }^{78}$ Persaingan ketat di bidang kedokteran gigi menuntut klinik gigi untuk memiliki strategi yang tepat agar dapat bersaing, dan salah satu strategi yang diperlukan adalah menciptakan kepuasan pasien pada klinik gigi. Tujuan dalam penelitian ini adalah untuk mengetahui pengaruh service quality secara parsial dan simultan terhadap kepuasan pasien ekspatriat Klinik Gigi Bali International Dental Center di Denpasar - Bali. Penelitian dilaksanakan pada klinik tersebut karena sudah dikenal sebagai klinik gigi yang merawat banyak pasien warga negara asing, sehingga dapat diperoleh responden yang sesuai dengan kriteria inklusi penelitian.

\section{METODE}

Penelitian ini dilakukan pada bulan pada bulan Juli Agustus 2017 di Klinik Gigi Bali International Dental Center di Denpasar - Bali. Jenis penelitian adalah a, disain penelitian yang digunakan adalah cross sectional study, dengan metode pengambilan sampel quota sampling. Populasi penelitian ini adalah seluruh pasien ekspatriat yang datang ke klinik Gigi Bali International Dental Center di Denpasar Bali. Besar sampel yang diambil dalam penelitian berjumlah 100 responden. Instrumen penelitian ini adalah quesioner. Penentuan jumlah sampel responden didasarkan pada pernyataan bahwa ukuran sampel yang baik dapat ditentukan dengan cara, jumlah pertanyaan dalam kuisioner dikali 5 (lima) sampai 10 (sepuluh). ${ }^{9}$ Variabel penelitian dibagi menjadi dua kelompok, yaitu variabel terikat (dependent variable): kepuasan pasien $(\mathrm{Y})$ dan 
variabel bebas (independent variable): Kualitas Pelayanan (SERVQUAL) yang meliputi Tangible (X1), Empathy (X2), Reliability (X3), Responsiveness (X4), dan Assurance (X5). Hipotesis penelitian diuji dengan menggunakan uji $\mathrm{F}$ dan uji $\mathrm{T}$. Metode analisis regresi linier berganda yang digunakan dalam penelitian ini berfungsi untuk mengetahui pengaruh atau hubungan dari variabel bebas dengan variabel terikat. Pengolahan data menggunakan alat bantusoftware SPSS 13.0.

Tabel 1. Karakteristik responden

\begin{tabular}{|c|c|c|}
\hline Kategori & Keterangan & Frekuensi \\
\hline \multirow[t]{2}{*}{ Jenis Kelamin } & Laki-laki & 54 \\
\hline & Perempuan & 46 \\
\hline \multirow[t]{6}{*}{ Usia } & $18-25$ & 14 \\
\hline & $26-35$ & 23 \\
\hline & $36-45$ & 22 \\
\hline & $46-55$ & 19 \\
\hline & $56-65$ & 14 \\
\hline & $>65$ & 8 \\
\hline \multirow[t]{18}{*}{ Kewarganegaraan } & Amerika Serikat & 26 \\
\hline & Australia & 19 \\
\hline & Perancis & 16 \\
\hline & Inggris & 9 \\
\hline & Rusia & 4 \\
\hline & Selandia Baru & 4 \\
\hline & Italia & 3 \\
\hline & Singapura & 3 \\
\hline & Afrika & 2 \\
\hline & Arab Saudi & 2 \\
\hline & Belanda & 2 \\
\hline & Cina & 2 \\
\hline & Swiss & 2 \\
\hline & Spanyol & 2 \\
\hline & Jepang & 1 \\
\hline & Jerman & 1 \\
\hline & Polandia & 1 \\
\hline & Malaysia & 1 \\
\hline \multirow[t]{4}{*}{ Pendidikan Terakhir } & SMA & 9 \\
\hline & Diploma & 20 \\
\hline & Universitas & 6 \\
\hline & Magister & 15 \\
\hline \multirow[t]{5}{*}{ Status Pekerjaan } & Purna Waktu & 62 \\
\hline & Paruh Waktu & 13 \\
\hline & Pelajar & 7 \\
\hline & Pensiun & 17 \\
\hline & Tidak Bekerja & 1 \\
\hline \multirow[t]{5}{*}{ Perawatan Gigi } & Penambalan & 25 \\
\hline & $\begin{array}{c}\text { Pemeriksaan Rutin \& } \\
\text { Pembersihan Karang Gigi }\end{array}$ & 19 \\
\hline & Perawatan Saluran Akar & 17 \\
\hline & Cosmetic Dentistry & 16 \\
\hline & Ekstraksi Gigi & 16 \\
\hline
\end{tabular}




\begin{tabular}{lcc}
\hline & Crown \& Bridge & 15 \\
& Gigi Tiruan & 8 \\
Sumber Informasi Klinik & Pelayanan Darurat & 2 \\
& Lainnya & 7 \\
\hline
\end{tabular}

\section{HASIL}

Secara keseluruhan, tanggapan responden mengenai Expectations sangat tinggi sebesar 85,3\% dan tanggapan responden mengenai Performance juga dalam kategori sangat tinggi sebesar $85,0 \%$. Skor Performance sudah mendekati skor Expectations dengan perbedaan skor sebesar 0,3\%. Sehingga dapat disimpulkan bahwa secara keseluruhan service quality Klinik Gigi Bali International Dental Centre sudah sangat baik dan sesuai dengan ekspektasi pasien. Namun, secara spesifik terdapat 3 variabel yang belum memenuhi ekspektasi pelanggan yaitu variabel Empathy, Responsiveness, dan Assurance.

Tabel 2. Rekapitulasi tanggapan responden mengenai expectations dan performance

\begin{tabular}{lcc}
\hline Sub variabel & Skor expectation & Skor performance \\
\hline Tangibles (X1) & 1705 & 1823 \\
Empathy (X2) & 1735 & 1711 \\
Reliabilty (X3) & 1685 & 1688 \\
Responsiveness (X4) & 1661 & 1610 \\
Assurance (X5) & 1747 & 1671 \\
Total & 8533 & 8503 \\
Persentase & $85,3 \%$ & $85,0 \%$ \\
\hline
\end{tabular}

Tabel 3. Besarnya pengaruh secara parsial

\begin{tabular}{ccccc}
\hline Variabel & $\begin{array}{c}\text { Standarized } \\
\text { Coefficients }\end{array}$ & Correlations & Besarnya pengaruh secara parsial & $\begin{array}{c}\text { Besarnya pengaruh secara parsial } \\
\text { (\%) }\end{array}$ \\
\hline $\mathrm{X}_{1}$ & 0,156 & 0,51 & 0,080 & 8,0 \\
$\mathrm{X}_{2}$ & 0,244 & 0,771 & 0,188 & 18,8 \\
$\mathrm{X}_{3}$ & 0,191 & 0,836 & 0,159 & 15,9 \\
$\mathrm{X}_{4}$ & 0,355 & 0,802 & 0,285 & 28,5 \\
$\mathrm{X}_{5}$ & 0,185 & 0,787 & 0,146 & 14,6 \\
\hline
\end{tabular}

Pengaruh parsial diperoleh dengan mengalikan standardized coefficient beta dengan zero- order. Berdasarkan tabel di atas, dapat dilihat bahwa besarnya pengaruh tangibles (X1) terhadap kepuasan pasien (Y) secara parsial adalah sebesar 8,0\%, besarnya pengaruh emphaty (X2) terhadap kepuasan Pasien (Y) secara parsial adalah sebesar 18,8\%, besarnya pengaruh Reliability (X3) terhadap Kepuasan Pasien (Y) secara parsial adalah sebesar
15,9\%, besarnya pengaruh Responsiveness (X4) terhadap Kepuasan Pasien (Y) secara parsial adalah sebesar 28,5\%, besarnya pengaruh Assurance (X5) terhadap Kepuasan Pasien (Y) secara parsial adalah sebesar 14,6\%. Jadi, total keseluruhan pengaruh Tangibles (X1), Emphaty (X2), Reliability (X3), Responsiveness (X4) dan Assurance (X5) Terhadap Kepuasan Pasien (Y) secara bersama-sama adalah sebesar $85,8 \%$. 


\begin{tabular}{ccccc}
\hline \multicolumn{5}{c}{ Tabel 4. Analisis regresi berganda } \\
\cline { 1 - 4 } Variabel & $\begin{array}{c}\text { Koefisien } \\
\text { Regresi }\end{array}$ & $\begin{array}{c}\text { Std } \\
\text { Error }\end{array}$ & $\mathbf{t}$ & Sig. \\
\cline { 1 - 5 } (Constant) & 0,223 & 0,038 & 5,909 & 0,000 \\
\cline { 1 - 1 } $\mathrm{X}_{1}$ & 0,034 & 0,013 & 2,688 & 0,008 \\
\cline { 3 - 5 } $\mathrm{X}_{2}$ & 0,058 & 0,017 & 3,412 & 0,001 \\
\hline $\mathrm{X}_{3}$ & 0,040 & 0,016 & 2,486 & 0,015 \\
\hline $\mathrm{X}_{4}$ & 0,071 & 0,014 & 5,048 & 0,000 \\
\hline $\mathbf{X}_{\mathbf{5}}$ & $\mathbf{0 , 0 3 7}$ & $\mathbf{0 , 0 1 5}$ & $\mathbf{2 , 5 4 5}$ & $\mathbf{0 , 0 1 3}$ \\
\hline
\end{tabular}

Hasil perhitungan pada tabel di atas, diperoleh bentuk persamaan regresi linier berganda sebagai berikut: $\mathrm{Y}=0,223+0,034 \mathrm{X} 1+0,058 \mathrm{X} 2+0,040 \mathrm{X} 3+$ $0,071 \mathrm{X} 4+0,037 \mathrm{X} 5+$ Errorvar. $=0,142+\mathrm{R}^{2}=0,858$. Persamaan tersebut menunjukkan bahwa variabel $\mathrm{Y}$ dipengaruhi oleh $\mathrm{X} 1, \mathrm{X} 2, \mathrm{X} 3, \mathrm{X} 4$, dan $\mathrm{X} 5$ dengan nilai koefisien regresi pada masing-masing variabel tertera sebelum variabel. Nilai koefisien regresi pada variabel-variabel bebasnya menggambarkan apabila diperkirakan variabel bebas naik sebesar satu unit dan nilai variabel bebas lainnya diperkirakan konstan atau sama dengan nol, maka nilai variabel terikat diperkirakan bisa naik atau bisa turun sesuai dengan tanda koefisien regresi variabel bebasnya.

Nilai persamaan regresi linier berganda diatas diperoleh nilai konstanta sebesar 0,223 , artinya, jika variabel kepuasan Pasien (Y) tidak dipengaruhi oleh kelima variabel bebasnya yaitu tangibles ( $\left.\mathrm{X}_{1}\right)$, emphaty (X2), reliability (X3), responsiveness (X4) dan assurance ( $\mathrm{X}_{5}$ ) bernilai nol, maka besarnya ratarata $\mathrm{Y}$ akan bernilai 0,223 .

Tanda koefisien regresi variabel bebas menunjukkan arah hubungan dari variabel yang bersangkutan dengan Kepuasan Pasien. Koefisien regresi untuk variabel bebas $\mathrm{X}_{1}$ bernilai positif, menunjukkan adanya hubungan yang searah antara tangibles (X1) dengan Kepuasan Pasien (Y). Koefisien regresi variabel $\mathrm{X}_{1}$ sebesar 0,034 mengandung arti untuk setiap pertambahan Tangibles (X1) sebesar satu satuan akan menyebabkan meningkatnya kepuasan pasien (Y) sebesar 0,034.

Koefisien regresi untuk variabel bebas X2 bernilai positif, menunjukkan adanya hubungan yang searah antara emphaty (X2) dengan kepuasan pasien $(\mathrm{Y})$. Koefisien regresi variabel $\mathrm{X} 2$ sebesar 0,058 mengandung arti untuk setiap pertambahan emphaty (X2) sebesar satu satuan akan menyebabkan meningkatnya kepuasan pasien (Y) sebesar 0,058. Koefisien regresi untuk

variabel bebas $\mathrm{X} 3$ bernilai positif, menunjukkan adanya hubungan yang searah antara reliability (X3) dengan kepuasan pasien (Y). Koefisien regresi variabel X3 sebesar 0,040 mengandung arti untuk setiap pertambahan reliability (X3) sebesar satu satuan akan menyebabkan meningkatnya kepuasan pasien $(Y)$ sebesar 0,040. Koefisien regresi untuk variabel bebas $\mathrm{X} 4$ bernilai positif, menunjukkan adanya hubungan yang searah antara responsiveness (X4) dengan kepuasan pasien (Y). Koefisien regresi variabel $\mathrm{X} 4$ sebesar 0,071 mengandung arti untuk setiap pertambahan responsiveness (X4) sebesar satu satuan akan menyebabkan meningkatnya kepuasan pasien $(Y)$ sebesar 0,071. Koefisien regresi untuk variabel bebas $\mathrm{X} 5$ bernilai positif, menunjukkan adanya hubungan yang searah antara assurance (X5) dengan Kepuasan Pasien (Y). Koefisien regresi variabel $X_{5}$ sebesar 0,037 mengandung arti untuk setiap pertambahan assurance (X5) sebesar satu satuan akan menyebabkan meningkatnya kepuasan pasien $(\mathrm{Y})$ sebesar 0,037. Selain koefisien regresi, persamaan struktural diatas juga menunjukkan informasi mengenai $\mathrm{R}^{2}$ dan error variance. $\mathrm{R}^{2}$ yang bernilai 0,858 menunjukkan bahwa $85,8 \%$ dari $Y$ sudah dijelaskan melalui variabel-variabel yang memengaruhi $\mathrm{Y}$ pada penelitian ini. Sedangkan $14,2 \%$ sisanya dijelaskan dengan error variance. Terdapat kemungkinan bahwa masih ada variabel lain yang tidak digunakan pada penelitian ini dapat menjelaskan Y.

\section{PEMBAHASAN}

Ha1 : tangibles ( $\left.\mathrm{X}_{1}\right)$ berpengaruh secara signifikan terhadap kepuasan pasien (Y). Hubungan antara variabel tangibles dan kepuasan pasien memiliki nilai $t$ hitung $(2,688)$ yang lebih besar dari $t$ tabel $(1,986)$. Hal tersebut memiliki arti bahwa tangibles memengaruhi kepuasan pasien secara positif dan signifikan, yang artinya Ha1 diterima. Hal ini membuktikan bahwa klinik gigi yang terlihat menarik secara visual, staf klinik yang berpenampilan rapi, mengikuti perkembangan perawatan dan teknologi terkini, serta peralatan klinik gigi yang moderen memengaruhi kepuasan pasien.

Jawaban responden terhadap kolom pertanyaan terbuka pada bagian akhir kuisioner, $16 \%$ responden berpendapat bahwa lahan parkir di Klinik Gigi Bali International Dental Center terbatas, 
sehingga responden yang membawa kendaraan pribadi sulit untuk mendapatkan tempat parkir. Alangkah baiknya apabila klinik gigi menyediakan lahan parkir yang memadai dan membuat sistem parkir yang efisien agar dapat memenuhi kebutuhan pasien sehingga kepuasan pasien terhadap aspek tangibles klinik dapat meningkat.

Ha2 : empathy (X2) berpengaruh secara signifikan terhadap kepuasan pasien (Y). Hubungan antara variabel empathy dan kepuasan pasien memiliki nilai t hitung $(3,412)$ yang lebih besar dari t tabel $(1,986)$. Hal tersebut memiliki arti bahwa empathy memengaruhi kepuasan pasien secara positif dan signifikan, yang artinya Ha2 diterima. Hal ini membuktikan bahwa sikap fleksibel staf klinik dalam melayani kebutuhan pasien, komunikasi antara dokter gigi dan pasien yang baik, serta perawatan yang tidak menyakitkan memengaruhi kepuasan pasien.

Sebesar $13 \%$ responden dalam kolom pertanyaan terbuka menjawab bahwa mereka sangat puas dengan pelayanan klinik gigi Bali International Dental Centre dalam hal komunikasi dokter dan staf klinik dengan pasien. Pasien yang memiliki keterbatasan dalam berkomunikasi menggunakan Bahasa Indonesia merasa sangat terbantu dengan kemampuan komunikasi Bahasa Inggris para dokter gigi dan staf klinik. Hal tersebut dapat membantu untuk menghindari adanya kesalahpahaman antara dokter gigi dan staf klinik dengan pasien, serta meningkatkan pemahaman pasien mengenai perawatan yang dijalani. Hal tersebut didukung oleh penelitian yang telah dilakukan sebelumnya, bahwa peran komunikasi interpersonal antara dokter gigi dan pasien sangat penting untuk menciptakan proses layanan medik gigi dan mulut yang optimal. ${ }^{10}$

Ha3 : reliability (X3) berpengaruh secara signifikan terhadap kepuasan pasien (Y). Hubungan antara variabel reliability terhadap kepuasan pasien memiliki nilai t hitung $(2,486)$ yang lebih besar dari t tabel $(1,986)$. Hal tersebut memiliki arti bahwa Reliability memengaruhi Kepuasan Pasien secara positif dan signifikan, yang artinya Ha3 diterima. Hal ini mendukung indikator dalam penelitian ini bahwa penjadwalan janji temu dengan dokter gigi pada waktu yang tepat, dokter gigi yang tepat waktu, kepercayaan pasien terhadap keterampilan dokter gigi yang merawat, serta perawatan gigi yang berkualitas tinggi memengaruhi kepuasan pasien.

Ha4 : responsiveness $(\mathrm{X} 4)$ berpengaruh secara signifikan terhadap kepuasan pasien (Y). Hubungan antara variabel responsiveness terhadap kepuasan pasien memiliki nilai t hitung $(5,048)$ yang lebih besar dari $\mathrm{t}$ tabel $(1,986)$. Hal tersebut memiliki arti bahwa responsiveness memengaruhi Kepuasan Pasien secara positif dan signifikan, yang artinya Ha4 diterima. Hal ini mendukung pernyataan pada penelitian ini bahwa masa tunggu perawatan yang singkat, ketersediaan dokter gigi dalam keadaan darurat, staf klinik yang sigap dalam menanggapi permintaan pasien, dan pemberitahuan pihak staf klinik mengenai kapan perawatan akan dilakukan memengaruhi kepuasan pasien. Sebanyak 14\% responden yang mengisi kolom pertanyaan terbuka berpendapat bahwa staf Klinik Gigi Bali International Dental Center cukup responsif dalam menanggapi berbagai kebutuhan dan permintaan pasien, seperti memesankan taksi untuk pasien, menolong pasien yang memerlukan bantuan untuk ke toilet, dan mengantarkan pasien ke ruang perawatan.

Ha5 : Assurance (X5) berpengaruh secara signifikan terhadap Kepuasan Pasien (Y). Hubungan antara variabel Assurance terhadap Kepuasan Pasien memiliki nilai t hitung $(2,545)$ yang lebih besar dari $\mathrm{t}$ tabel $(1,986)$. Hal tersebut memiliki arti bahwa Assurance memengaruhi Kepuasan Pasien secara positif dan signifikan, yang artinya Ha5 diterima. Hal ini mendukung pernyataan pada penelitian ini bahwa penjelasan dokter gigi mengenai masalah gigi pasien pada kunjungan pertama, dokter gigi menjelaskan prosedur perawatan, dokter gigi melakukan tindakan pencegahan untuk melindungi pasien dari penyakit menular, dan resepsionis yang selalu teratur dalam mengatur jadwal janji temu memengaruhi kepuasan pasien.

Penelitian ini menggunakan lima dimensi variabel Service Quality menurut Parasuraman yang meliputi Tangibles, Empathy, Reliability, Responsiveness, dan Assurance. Pada penelitian selanjutnya dapat menggunakan dimensi Service Quality dengan modifikasi lainnya agar dapat mencakup variabel-variabel yang belum diteliti dalam penelitian ini, seperti variabel harga / biaya perawatan.

Rekomendasi saran yang dapat diberikan berdasarkan hasil penelitian yang dilakukan oleh peneliti adalah penelitian selanjutnya, sampel penelitian dapat diambil dari berbagai wilayah dan berbagai penyedia pelayanan kesehatan gigi; dalam penelitian ini belum melibatkan variabel 
harga/biaya perawatan, sehingga dalam penelitian berikutnya variabel tersebut dapat dilibatkan.; penelitian selanjutnya dapat diteliti mengenai tingkat ekspektasi dan kepuasan tertinggi berdasarkan latar belakang dari kewarganegaraan pasien.; untuk meningkatkan kenyamanan dan kepuasan pasien di Klinik Gigi Bali International Dental Center, dapat dilakukan dengan sistem parkir kendaraan yang lebih maksimal dan efisien.

\section{SIMPULAN}

Kepuasan pasien merupakan persyaratan fundamental bagi penyedia layanan kesehatan. Service quality berpengaruh signifikan terhadap kepuasan pasien. Variabel tangibles (X1) memiliki pengaruh terkecil terhadap kepuasan pasien, sedangkan variabel responsiveness (X4) memiliki pengaruh terbesar terhadap kepuasan pasien.

\section{DAFTAR PUSTAKA}

1. Hwang SY, Goong HS, Kim KE. Determination Factors of Dental Clinics of Foreigners Residing in Korea. Department of Preventive and Social Dentistry School of Dentistry Kyung Hee University Korea. 2015.

2. Siswaningsih D. Peluang dan Tantangan Indonesia Pasar Bebas ASEAN. Kementerian Perdagangan Republik Indonesia. 2015.

3. Masyarakat Ekonomi ASEAN. Kementerian Luar Negeri Republik Indonesia; 2015. Available from: https://www.kemlu.go.id/ id/kebijakan/asean/Pages/MasyarakatEkonomi- ASEAN-(MEA).aspx

4. KBBI. Kamus Besar Bahasa Indonesia (KBBI). $6^{\text {th }}$ ed. Jakarta. 2016

5. Direktorat Jenderal Binapenta. Penggunaan Tenaga Kerja Asing Di Indonesia. Pusdatinaker; 2010.

6. Huguet JW, Martin PL. Asia-Pacific Migration Report Migrants' Contributions to Development. 2015.

7. Petersen PE. The World Oral Report: Continous Improvement of Oral Health in the 21st Century - the Approach of the WHO Global Oral Health Programme. Blackwell Munksgaard. 2003.

8. Veerasoontorn R, Beise-Zee R. International Hospital Outshopping : A Staged Model of Push and Pull Factors. Emerald Group Publication Ltd. 2014.

9. Stewart M. Effective Physician-Patient Communication and Health Outcomes: A Review. 1995.

10. Beck I, McKeown M, Kucan L. Bringing Words to Life : Robust Vocabulary.New York: Guilford Press. 2012.

11. Lewis RC, Booms BH. The Marketing Aspect of Service Quality in Emerging Perspectives on Services Marketing. American Marketing. 1983.

12. DeVrye C. Good Service is Good Business. 7 Strategi Sederhana Menuju Sukses. Jakarta: PT Gramedia Pustaka Utama. 2003.

13. Tjiptono F. Chandra G. Service, Quality and Satisfaction. (4th ed.) Yogyakarta: Andi. 2016.

14. Menteri Kesehatan Republik Indonesia. Peraturan Menteri Kesehatan Republik Indonesia Nomor 9 Tahun 2014 Tentang Klinik. Jakarta. 2014.

15. Malhotra NK. Marketing Research : An Applied Orientation. (6th ed.). Pearso. 2009. 